\title{
Massive pulmonary embolism or something else in the pulmonary artery truncus?
}

\section{Marija Brestovac*, Vlatka Rešković Lukšić, \\ Blanka Glavaš Konja, Joško Bulum, \\ Martina Lovrić Benčić, Marko Jakopović, Jadranka Šeparović Hanževački}

University of Zagreb School of Medicine, University Hospital Centre Zagreb, Zagreb, Croatia
KEYWORDS: pulmonary embolism, angiosarcoma, anticoagulant therapy. CITATION: Cardiol Croat. 2017;12(4):153. | https://doi.org/10.15836/ccar2017.153

*ADDRESS FOR CORRESPONDENCE: Marija Brestovac, Klinički bolnički centar Zagreb, Kišpatićeva 12, HR-10000 Zagreb, Croatia. / Phone: +385-99-7742-627 / E-mail: marija.brestovac@gmail.com

ORCID: Marija Brestovac, http://orcid.org/0000-0003-1542-2890 • Vlatka Rešković Lukšić, http://orcid.org/0000-0002-4721-3236 Blanka Glavaš Konja, http://orcid.org/0000-0003-1134-4856 • Joško Bulum, http://orcid.org/0000-0002-1482-6503 Martina Lovrić Benčić, http://orcid.org/0000-0001-8446-6120 • Jadranka Šeparović Hanževački, http://orcid.org/0000-0002-3437-6407 IIIIIIIIIIIIIIIIIIIIIIIIIIIIIIIIIIIIIIIIIIIIIIIIIIIIIIIIIIIIIIIIIIIIIIIIIIIIIIIIIIIIIIIIIIIIIIIIIIIIIIIIIIIIIIIIIIIIIII Introduction: Pulmonary embolism is frequently seen in malignant diseases and requires anticoagulant treatment ${ }^{1}$. The decision on fibrinolytic therapy is based mainly on hemodynamic state of the patient.

Case report: 56-year-old female patient was admitted to our department because of severe dyspnea and chest pain. She was a heavy smoker and few years ago she underwent chemotherapy and surgical treatment for colorectal carcinoma, maintaining complete remission. Five months' prior admission she started complaining of dyspnea, dry cough, pain in the left hemithorax, inappetence and significant weight loss Among other diagnostic tests, pulmonary CT angiography was performed and massive pulmonary embolism was diagnosed. At the time of admission, the patient was hemodynamically stable and D-dimer values were only slightly elevated ( $2 \mathrm{mg} / \mathrm{l})$. According to patient history, it was more likely that she had had chronic pulmonary embolism, so we decided to start therapy with low molecular weight heparin and warfarin, rather than fibrinolytic therapy. Echocardiography findings revealed severe right heart pressure overload with mild cavity dilatation, preserved systolic function, mild to moderate tricuspid regurgitation and a massive thrombus in truncus of the pulmonary artery (PA) with signs of pulmonary valve (PV) obstruction (Figure 1). There were no signs of deep vein thrombosis nor relapse of colorectal carcinoma. After adequate anticoagulation, 11 days later, echocardiography revealed progression of the obstructive mass in the PA trunc. However, the patient was still hemodynamically stable and eupneic. Even though a fibrinolytic therapy was considered again, we decided against that treatment option. A CT pulmonary angiography was repeated and showed signs of pulmonary artery angiosarcoma: an endoluminal mass infiltrating pulmonary valve up to the pulmonary artery bifurcation, lobar and segmental branches and with suspected pulmonary infarction without mediastinal lymphadeopathy (Figure 2). The patient was transferred to department for lung diseases. PET/CT body scans showed metabolic activity in the pulmonary artery mass and a lymph node above the pulmonary artery while cytological findings taken during secondary carina punction revealed

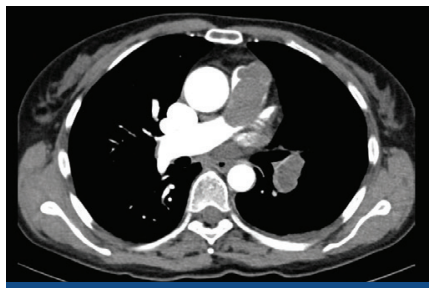

FIGURE 2. Computerized tomography scan: proliferative mass of pulmonary artery truncus.

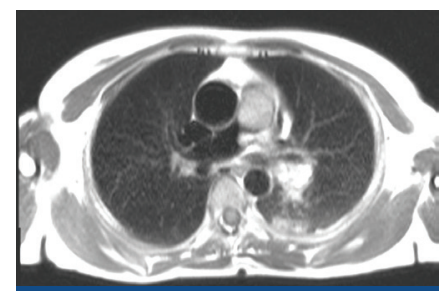

FIGURE 3. Magnetic resonance angiography: proliferative mass of pulmonary artery truncus. mesenchymal malignant neoplasia. A MR scan of the heart and pulmonary MR angiography described a partially necrotic mass attached to pulmonary valve without myocardial infiltration (Figure 3). Considering the complexity of the case a definite treatment decision is going to be made by a medical council including cardiologists, pulmonologists and cardiac surgeons ${ }^{2,3}$

Conclusion: Although pulmonary embolism may accompany malignant diseases, other etiologies of the infiltration of the pulmonary artery should also be taken into account, especially when considering fibrinolytic therapy. Regular echo follow-up is helpful in visualizing the thrombus regression under anticoagulant therapy as well as setting indications for further diagnostic and treatment options.

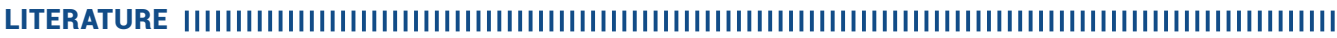

1. Mitrugno A, Tormoen GW, Kuhn P, MCCarty 0J. The prothrombotic activity of cancer cells in the circulation. Blood Rev. 2016 Jan;30(1):11-9. https://doi.org/10.1016/j.blre.2015.07.001

2. Ren Y, Zhu M, Liu Y, Diao X, Zhang Y. Primary pulmonary angiosarcoma: Three case reports and literature review. Thorac Cancer. 2016 Sep;7(5):607-613. https://doi.org/10.1111/1759-7714.12376

3. Kojima K, Okamoto I, Ushijima S, Yoshinaga T, Kitaoka M, Suga M, Sasaki Y. Successful treatment of primary pulmonary angiosarcoma. Chest. 2003 Dec;124(6):2397-400. https://doi.org/10.1378/chest.124.6.2397 